Running head: SPECIFIC JOB SEARCH SELF-EFFICACIES AND BEHAVIORS

\title{
Specific Job Search Self-Efficacy Beliefs and Behaviors of Unemployed Ethnic Minority Women
}

\author{
Greet Van Hoye \\ Ghent University, Belgium \\ Edwin A. J. van Hooft \\ University of Amsterdam, The Netherlands \\ Jolien Stremersch \\ Ghent University, Belgium \\ Filip Lievens
}

Singapore Management University

Citation: Van Hoye, G., Van Hooft, E. A. J., Stremersch, J., \& Lievens, F. (2019). Specific job search self-efficacy beliefs and behaviors of unemployed ethnic minority women. International Journal of Selection and Assessment, 27, 9-20. doi: https://doi.org/10.1111/ijsa.12231

This research was supported by the European Social Fund under grant 04/EQ/1.A/016 and by the Research Foundation Flanders (FWO) under grant 3E019209. Parts of the paper were presented at the $73^{\text {rd }}$ Annual Meeting of the Academy of Management, Lake Buena Vista, FL (2013, August). We would like to thank Connie Wanberg for her valuable comments on a prior version of the paper. The authors declare no conflict of interest.

Correspondence concerning this paper should be addressed to Greet Van Hoye, Department of Marketing, Innovation, and Organization, Ghent University, Tweekerkenstraat 2, 9000 Ghent, Belgium. Phone: +32.9.264.35.86. E-mail: greet.vanhoye@ugent.be 


\begin{abstract}
This two-wave field study draws from social cognitive theory to investigate the specific job search self-efficacy beliefs and behaviors of unemployed ethnic minority women in the Netherlands. We go beyond prior job search research that predominantly used white samples and conceptualized job search self-efficacy and behavior as global, unidimensional constructs. We found that networking self-efficacy and Internet self-efficacy were the main predictors of ethnic minority women's job search behaviors. Moreover, the more time they spent on contacting employment agencies and looking at job ads the more job offers they received. Finally, time spent on job ads was more positively related to job offers when job ad self-efficacy was high and time spent on networking only predicted job offers when networking self-efficacy was high.
\end{abstract}

Keywords: Unemployment; job search; job search behavior; self-efficacy; ethnic minority women. 


\section{Specific Job Search Self-Efficacy Beliefs and Behaviors of Unemployed Ethnic Minority Women}

In most countries, ethnic minority groups are substantially more likely to suffer from unemployment than the ethnic majority group (Byars-Winston, Fouad, \& Wen, 2015). Furthermore, although official unemployment rates among women and men are roughly similar nowadays, women are still less likely to participate in the labour market, and are more likely to be "underemployed", as indicated by lower wages, lower-level jobs, and more part-time employment (Shen et al., 2017). This implies that ethnic minority women are particularly at risk and are confronted with particular challenges with respect to their employment and career development (Kamenou \& Fearfull, 2006). For instance, in the Netherlands, where our study was conducted, $9.0 \%$ of ethnic minority women were unemployed in 2017 , which is considerably higher than the overall average unemployment rate of $4.9 \%$ (native men $3.5 \%$, native women 4.3\%, ethnic minority men $8.1 \%$; CBS, 2018).

However, similar to behavioral sciences in general, studies on job seeking are largely based on white samples, the results of which might not generalize to ethnic minority samples (Henrich, Heine, \& Norenzayan, 2010). If we want to stimulate reemployment and offer effective vocational guidance and training towards specific groups vulnerable for long-term unemployment such as ethnic minority women, we need to understand how they search for jobs and how effective these behaviors are. Therefore, the first objective of the present study was to examine to what extent previous findings on the positive relationship of job search behavior with employment outcomes (Kanfer, Wanberg, \& Kantrowitz, 2001) generalize to ethnic minority women. This is an important question for examination as some research suggests that job search behavior might not universally predict employment outcomes (e.g., Šverko, Galić, Seršić, \& Galešić, 2008; Van Hooft, Born, Taris, \& Van der Flier, 2004a). 
Second, we need to know how the use and effectiveness of job search behaviors among ethnic minority women can be advanced. Social cognitive theory offers a relevant theoretical perspective here, as it accords a central role to self-efficacy beliefs in explaining human motivation and behavior (Bandura, 1991). Importantly, self-efficacy is malleable, and can be increased through training (e.g., Bandura, 2001; Liu, Huang, \& Wang, 2014). In line with social cognitive theory, meta-analytic findings show that job search self-efficacy is a key predictor of job search behavior (Kanfer et al., 2001), which explains the effectiveness of job search interventions (Liu et al., 2014). Again, these findings are largely based on the general job seeker population, raising issues of generalizability. Therefore, as a second objective, we examine to what extent previous findings on the predicting role of self-efficacy for job search behavior generalize to ethnic minority women.

As a third objective, the present study aims to advance our theoretical understanding on the prediction and effectiveness of specific job search behaviors. Although some evidence suggests that job seekers differ in their use of specific job search methods (Wanberg, Glomb, Song, \& Sorenson, 2005) and that the determinants and outcomes of job search depend on the applied search behaviors (Van Hoye \& Saks, 2008), prior research has typically treated job search behavior and job search self-efficacy as global, unidimensional constructs. Such measures aggregate across many different job search activities, even though job seekers' frequency of use and self-efficacy beliefs for some of these behaviors are likely to differ (e.g., looking for jobs on the Internet versus networking). As a result, we know little about which specific job search behaviors contribute most to job search success, and how the most effective search behaviors might best be stimulated, even in the general job seeker population. Some scarce previous research provided indications that various job search behaviors may differ in their effectiveness (Van Hoye, Van Hooft, \& Lievens, 2009). However, it is yet unknown which specific job search 
behaviors are more or less effective for ethnic minority women. In order to improve vocational counselling methods and interventions, we need to obtain specific understanding of which job search methods work best among these women.

Therefore, the current study examines how the time spent by unemployed ethnic minority women on four prevalent specific job search behaviors (i.e., networking, contacting employment agencies, looking at job ads in newspapers or journals, and looking for job openings on the Internet) relates to the number of job offers they receive. In addition, we investigate four corresponding specific job search self-efficacy beliefs (i.e., networking self-efficacy, agency selfefficacy, job ad self-efficacy, and Internet self-efficacy) as predictors of the use of these job search behaviors and as moderators of their effectiveness. On a theoretical level, we contribute to the job search literature by distinguishing between multiple specific job search behaviors and self-efficacies, thus addressing the specific content and direction of job search (Kanfer et al., 2001). On a practical level, we demonstrate the value of such a multidimensional approach in the context of unemployed ethnic minority women's job search, offering key practical implications for stimulating their reemployment.

\section{Job Search Behavior and Job Offers}

Although receiving job offers and finding reemployment importantly depends on structural factors such as labour market demand, employer discrimination, and job seeker human and social capital (Wanberg, Hough, \& Song, 2002), previous research also identified various cognitive and behavioral determinants that are more controllable by the individual job seeker. For example, a meta-analysis of the job search and unemployment literature found that job search behavior is a major determinant of employment outcomes (Kanfer et al., 2001).

Job search is conceptualized as a highly self-regulatory process that begins with the identification of and commitment to an employment goal (Kanfer et al., 2001). This goal 
subsequently activates different job search behaviors designed to bring about the desired goal, such as looking up job ads and contacting employment agencies. Kanfer et al. (2001) further theorized that job search behavior can be described along three major dimensions: effort-intensity (overall effort and frequency of job search activity), content-direction (specific activities engaged in and quality of these activities), and temporal-persistence (dynamic processes and persistence in job search). Whereas previous research has mainly focused on the overall intensity of job search behavior (i.e., the first dimension) and more recent studies (e.g., Wanberg, Zhu, \& Van Hooft, 2010) increasingly apply a dynamic approach to job search (i.e., the third dimension), almost no research focused on job seekers' use of specific job search behaviors (i.e., the second dimension). Such research that examines the content and direction of job search is important because differences in the use and effectiveness of various search behaviors are likely to exist, and these cannot be studied when only the overall intensity of job search is considered (Van Hoye \& Saks, 2008).

Based on previous research (e.g., Blau, 1994; Van Hoye et al., 2009; Wanberg et al., 2002) we focused on the content of job search behavior by distinguishing between four specific activities: networking, contacting employment agencies, looking at job ads in newspapers or journals, and looking for job openings on the Internet. By devoting more time and effort towards each of these activities, job seekers cast a wider territory of the labour market, resulting in increased chances of receiving job offers (Saks, 2006). Prior research among unemployed job seekers offered some support for this prediction for networking, which was found to relate positively to job offers (Van Hoye et al., 2009; Wanberg, Kanfer, \& Banas, 2000). However, empirical support for the other specific job search behaviors is scarce. For example, Van Hoye et al. (2009) reported that relying on public employment agencies was positively related to job 
offers, while looking at printed job advertisements and looking for job openings on the Internet were not.

An important remaining question is to what extent these earlier findings apply to ethnic minority women. Regarding networking, for example, Van Hoye et al. (2009) found that its effects seemed to depend on the quality of the contacts in job seekers' social networks (e.g., occupational status). Given that the social networks of women as well as ethnic minorities typically consist of lower-quality ties than those of white males (McDonald, Lin, \& Ao, 2009), networking may be less effective. In addition, the job search behaviors of ethnic minority women might be less strongly related to receiving job offers due to hiring discrimination (Derous, Ryan, \& Nguyen, 2012). Nevertheless, even given these issues it can be expected that when ethnic minority women spend more rather than less time on various job search activities they likely reach more job leads and more information about these job leads. This increased amount of information enables ethnic minority women to submit more and better informed applications, thus increasing their chances of receiving job offers. Therefore, positive relationships of all four job search behaviors with job offers may be expected.

H1: Time spent by ethnic minority women on (a) networking, (b) contacting employment agencies, (c) looking at job ads in newspapers or journals, and (d) looking for job openings on the Internet will be positively related to the number of job offers they receive.

\section{Social Cognitive Theory and Job Search Self-Efficacy}

Social cognitive theory reflects an agentic perspective in which people operate as anticipative, purposive, and self-evaluating proactive regulators of their motivation and actions (Bandura, 2001). In this view self-efficacy plays a key role, as Bandura and Locke (2003) argued that "whatever other factors serve as guides and motivators, they are rooted in the core belief that one has the power to produce desired effects; otherwise one has little incentive to act or to 
persevere in the face of difficulties" (p.87). Self-efficacy is thought to regulate human functioning through cognitive, motivational, affective, decisional, and behavioral processes (Bandura, 1991). The stronger people believe in their own capabilities, the greater and more persistent their efforts will be and the more likely they are to perform successfully (Bandura, 2001). Importantly, self-efficacy is a universal construct, applicable across many different cultural groups and contexts: "Not only is the structure of efficacy beliefs comparable crossculturally, but so are their functional properties" (Bandura, 2002, p. 281).

Social cognitive theory has already been applied to describe the career development of ethnic minority women, suggesting that their career self-efficacy beliefs are typically lower than those of the majority group and that enhancing these beliefs through counselling and training might be key to advancing their careers (Hackett \& Byars, 1996; Luzzo \& McWhirter, 2001). Given that job search is largely self-directed and allows substantial individual latitude in initiating actions (Van Hooft et al., 2004a), a social cognitive theory perspective seems particularly relevant for understanding ethnic minority women's job search behavior. Within a job search context, job search self-efficacy is defined as job seekers' belief or confidence that they can successfully accomplish particular job search activities (Kanfer et al., 2001). Some evidence shows that the job search self-efficacy beliefs of ethnic minority groups (Van Hooft et al., 2004a) and of women (Van Hooft, Born, Taris, \& Van der Flier, 2005) are lower than those of the ethnic majority group and men, respectively. This suggests that improving ethnic minority women's job search selfefficacy beliefs might play a crucial role in advancing their job search.

Whereas most research found job search self-efficacy to be a positive predictor of job search behavior (Kanfer et al., 2001), there is variation in the effect sizes and some studies have even reported nonsignificant relationships. One possible explanation for these mixed findings might be that the effects of job search self-efficacy depend on the specific population under study. For 
example, previous research found some indications that job search self-efficacy is a stronger predictor of job search behavior among unemployed people and those with low levels of job search experience (Van Hooft et al., 2004a, Van Hooft, Born, Taris, Van der Flier, \& Blonk, 2004b). Because of the generally higher levels of unemployment and lower levels of education among ethnic minority women, job search self-efficacy is expected to be a relevant predictor of job search behavior in this context.

Another possible explanation for the mixed findings might be that prior research looked at global job search self-efficacy, lumping together many different job search activities (Saks, Zikic, \& Koen, 2015). Given that divergent search activities such as looking for jobs on the Internet versus networking are likely to require different resources and skills, we argue that distinguishing between specific job search self-efficacies contributes to the prediction of specific job search behaviors and their effects. Therefore, in the current study, we propose that specific job search behaviors are predicted by the corresponding specific job search self-efficacies. This is consistent with Kanfer et al.'s (2001) conceptualization of the job search process, which suggests that the specific content and direction of job search behavior should be considered. Theoretically, this is also in line with Ajzen's (1991) principle for accurate prediction that measures of self-efficacy should correspond to the specific behavior of interest. To our knowledge, there is no prior research in the general job seeker population on the role of specific job search self-efficacy beliefs. Based on social cognitive theory and its functional cross-cultural commonality, and including the principle of correspondence we expect that ethnic minority women will be more likely to engage in specific job search behaviors if they feel more confident about successfully performing those same behaviors.

H2a: Networking self-efficacy beliefs will positively predict time spent on networking among ethnic minority women. 
H2b: Employment agency self-efficacy beliefs will positively predict time spent on contacting employment agencies among ethnic minority women.

H2c: Job ad self-efficacy beliefs will positively predict time spent on looking at job ads in newspapers or journals among ethnic minority women.

H2d: Internet self-efficacy beliefs will positively predict time spent on looking for job openings on the Internet among ethnic minority women.

Social cognitive theory further suggests that self-efficacy also impacts the quality with which people execute certain behaviors (Bandura, 2001), suggesting that self-efficacy affects the relationship between the use and the effectiveness of particular behaviors. In a job search context, the relationship between a particular search behavior and job offers is likely to be more positive for job seekers with higher self-efficacy beliefs for that specific behavior, as these beliefs relate to the quality and confidence with which the behavior is performed (Van Hooft, Wanberg, \& Van Hoye, 2013), increasing the likelihood that the behavior will be successful. There is some empirical evidence among student job seekers for a moderating impact of job search self-efficacy on the effectiveness of job search behavior. Specifically, Moynihan, Roehling, LePine, and Boswell (2003) observed that the relationship between the number of job interviews and job offers was stronger for graduating students with higher (global) job search self-efficacy beliefs, suggesting that more confident students were more effective in converting interviews into job offers. Based on these theoretical notions and empirical findings, we propose that self-efficacy for a specific job search behavior will moderate the relationship of that specific job search behavior with employment outcomes among ethnic minority women. For instance, some ethnic minority women in search of employment may feel comfortable with addressing personal contacts, but may not know their way around the Internet. These women will therefore more 
likely be successful when engaging in networking and less likely be successful when using the Internet to search for jobs.

H3a: The relationship between networking and job offers will be more positive for ethnic minority women with higher networking self-efficacy.

H3b: The relationship between contacting employment agencies and job offers will be more positive for ethnic minority women with higher agency self-efficacy.

H3c: The relationship between looking at job ads and job offers will be more positive for ethnic minority women with higher job ad self-efficacy.

H3d: The relationship between looking for job openings on the Internet and job offers will be more positive for ethnic minority women with higher Internet self-efficacy.

\section{Method}

\section{Sample and Procedure}

To temporally separate predictor and outcome variables, a two-wave design was applied. Job search self-efficacies were measured at Time 1, job search behaviors and job offers were assessed at Time 2, three months later. A three-month time interval was chosen to allow sufficient time for participants to engage in job search behaviors and receive reactions to their applications (Van Hoye, Saks, Lievens, \& Weijters, 2015). Our sample consisted of unemployed ethnic minority women in the Netherlands, who registered for job search counselling offered by a private reemployment counselling agency to this particular target group. Ethnic minority women were defined as women with a migration background originating from non-Western-European/NorthAmerican/Oceanian countries (CBS, 2016). At Time 1, participants were asked to complete a paper-and-pencil questionnaire during several group sessions. It was stressed that participation was voluntary and would in no way affect their official record, that answers would be treated confidentially and only used for research purposes, and that they should answer honestly, based 
on their own opinion or experiences, emphasizing that there were no wrong answers. It should be noted that the private reemployment counselling agency had nothing to do with issuing or controlling the unemployed women's social benefits. This was done by a different (governmental) institution independent of the counselling agency, further reducing concerns for social desirability responding. In total, 241 women filled out the Time 1 questionnaire. Although no exact response rate was recorded, it was almost $100 \%$, given that questionnaires were filled out during group sessions.

Three months after completing the Time 1 measures, participants were contacted by phone to answer a follow-up survey. This was done to enhance the response rate and to reduce common method bias, compared to administration by postal or electronic mail. The final sample at Time 2 consisted of 188 ethnic minority women, yielding a response rate of $78 \%$. Age ranged from 18 to 62 years $(M=36.28$ years, $S D=9.75)$. The majority of the sample was lower-educated with $74 \%$ having obtained only a primary school degree, $19 \%$ a high school degree, and $7 \%$ a college degree. Number of children ranged from 0 to $6(M=1.80, S D=1.45)$. At Time 2, 22\% of the women were reemployed. In the general Dutch population, $36 \%$ of job seekers receiving unemployment benefits generally find reemployment after three months (CBS, 2018). In a study investigating private reemployment counselling in the Netherlands, between $25 \%$ and $35 \%$ of participants found reemployment after six months (Tempelman, Berden, \& Kok, 2010).

A wide variety of ethnic minorities was represented in our sample with the largest groups originating from Morocco (19\%), Turkey (10\%), Ghana (9\%), Afghanistan (8\%), Somalia (7\%), Iraq (5\%), Iran (5\%), Pakistan (5\%), and Syria (4\%). The remainder of the participants originated from several other African (8\%), Southeast-Asian (8\%), Eastern-European (5\%), Middle-Eastern (3\%), Southeast-European (2\%), and South-American (2\%) countries. In the Netherlands, the largest non-Western groups have Turkish, Moroccan, Surinamese, and Antillean origins (CBS, 
2016). Women with a Turkish or Moroccan background were also the largest groups in our study. However, women with a Surinamese or Antillean background were not represented. Given that these two groups relate to the colonial history of the Netherlands, they mostly have Dutch as their first language, distinguishing them from other ethnic groups. Moreover, women with Surinamese or Antillean origins have higher employment rates than women with a Turkish or Moroccan background (CBS, 2016). Next to geographical reasons (people with a migration background live unevenly distributed across the country, CBS, 2016), this might explain why they were less likely to participate in the training offered by the reemployment counselling agency. In addition to these four largest groups, people with a non-Western migration background in the Netherlands increasingly include refugees, with the largest groups coming from Iraq, Afghanistan, Syria, Somalia, and Iran (CBS, 2016), all of which were represented in our study.

To check for selective nonresponse at Time 2, all Time 1 variables were entered in a logistic regression analysis predicting the probability of being included in the Time 2 sample. No indications for nonrandom sampling at Time 2 were observed, $\chi^{2}(8)=6.79, p=.56$.

\section{Time 1 Measures}

All items were rated on 5-point Likert-scales, ranging from 1=strongly disagree to 5=strongly agree.

Job search self-efficacy. Based on our Time 2 measures of job search behaviors, we developed four corresponding specific job search self-efficacy scales, consisting of two items each. Items were based on existing global job search self-efficacy scales (Ellis \& Taylor, 1983; Van Ryn \& Vinokur, 1992), and reworded to reflect self-efficacy for specific job search behaviors. Specifically, participants were asked to what extent they felt confident about being able to successfully carry out networking (e.g., “Asking people you know about possible job leads", networking self-efficacy, $\alpha=.88$ ), contacting employment agencies (e.g., "Contacting 
recruitment and selection agencies", agency self-efficacy, $\alpha=.73$ ), looking at printed job ads (e.g., "Looking for jobs in newspapers or journals", job ad self-efficacy, $\alpha=.74)$, and looking for job openings on the Internet (e.g., "Visiting job sites", Internet self-efficacy, $\alpha=.88$ ).

Confirmatory factor analyses showed that our hypothesized four-factor model of specific job search self-efficacies demonstrated an acceptable fit with the data, $\chi^{2}(14)=49.05, p<.001$, $\mathrm{CFI}=.94, \mathrm{SRMR}=.04, \mathrm{AIC}=4224.048$, while a model with one global job search self-efficacy factor showed a substantially worse fit, $\chi^{2}(20)=302.40, p<.001, \mathrm{CFI}=.53, \mathrm{SRMR}=.16$, $\mathrm{AIC}=4501.02 ; \Delta \chi^{2}(6)=253.35, p<.001$.

Demographic variables. All participants were unemployed women from an ethnic minority group. In addition, we controlled for age, education, and number of children in the analyses. ${ }^{1}$ Meta-analytic findings show that age is negatively related to job search self-efficacy, job search behavior, and employment outcomes (Wanberg, Kanfer, Hamann, \& Zhang, 2016), whereas education relates positively to job search behavior and employment success (Kanfer et al., 2001). Two dummy variables (primary school and college) were created to represent the three categories of education measured in our study, with the middle category (high school) used as the reference group. Furthermore, having children might pose additional job search constraints (e.g., needing affordable day care, Van Hoye \& Lootens, 2013). Along these lines, prior research suggests that having children can be negatively related to job search behavior and employment outcomes, especially for women (Van Hooft et al., 2005; Wanberg et al., 2002).

\section{Time 2 Measures}

Job search behavior. To identify relevant specific job search behaviors, we scrutinized composite measures of job search behavior used in previous research (Blau, 1994; Kanfer et al.,

\footnotetext{
${ }^{1}$ When we repeated the reported analyses without these control variables, similar results were obtained, leading to the same conclusions with respect to the hypotheses.
} 
2001; Van Hoye et al., 2009; Wanberg et al., 2000, 2002, 2005). In addition to networking, items frequently referred to reading job advertisements in newspapers or journals and contacting employment agencies. Recent studies supplemented these traditional job search behaviors with looking for job openings on the Internet (e.g., Wanberg et al., 2002). Next, we examined whether these four major job search behaviors were also representative of the job search conducted by unemployed ethnic minority women in the Netherlands. To this end, we consulted prior research conducted in comparable samples (Van Hooft et al., 2004a) and talked with several consultants of the Dutch private reemployment counselling agency working with these women. All of this indicated that unemployed ethnic minority women in the Netherlands also most commonly rely on networking, employment agencies, printed job advertisements, and the Internet in their job search.

Consistent with prior research (Van Hooft et al., 2004a, 2004b; Van Hoye et al. 2009, 2015), we measured the extent to which participants engaged in these four most prevalent specific job search behaviors by asking them to indicate how much time they had spent on each of these behaviors in the past three months or until they found a job. Specifically, four two-item scales developed by Van Hoye et al. (2009) were used. Items were rated on a 5-point rating scale, ranging from $1=$ no time at all to 5=very much time. Example items are "Contacting people you know to help you find a job" (networking, $\alpha=.80$ ), "Visiting the public employment office" (contacting employment agencies, $\alpha=.79$ ), "Reading job advertisements" (looking at printed job $a d s, \alpha=.75$ ), and "Visiting job boards or employer recruitment sites" (looking for job openings on the Internet, $\alpha=.89)$.

Confirmatory factor analyses showed that our hypothesized four-factor model of specific job search behaviors demonstrated an acceptable fit, $\chi^{2}(14)=61.77, p<.001, \mathrm{CFI}=.92, \mathrm{SRMR}=.05$, 
AIC $=3480.68$, while a model with one global job search behavior factor ${ }^{2}$ showed a substantially worse fit, $\chi^{2}(20)=160.37, p<.001, \mathrm{CFI}=.77, \mathrm{SRMR}=.08, \mathrm{AIC}=3577.83 ; \Delta \chi^{2}(6)=98.60, p<.001$.

Job offers. With respect to job search outcomes (Kanfer et al., 2001), respondents were asked to report the number of job offers they received in the past three months.

\section{Results}

Table 1 shows the means, standard deviations, and correlations. All four job search behaviors were positively correlated with job offers. All job search self-efficacies, except for job ad selfefficacy, were positively correlated with the corresponding job search behavior. To test the first set of hypotheses (H1a-d) regarding the relationship between specific job search behaviors and job offers, a hierarchical regression analysis was conducted with number of job offers as dependent variable. The control variables were added in the first step and the four job search behaviors in the second step. As shown in Table 2, ethnic minority women with more children received less job offers $(\beta=-.19, p=.04)$. In Step 2, the specific job search behaviors together explained $32.8 \%$ of incremental variance, $F(4,146)=19.23, p<.001$. While the zero-order correlations showed positive relationships for all four job search behaviors, the regression analysis indicated that only contacting employment agencies $(\beta=.33, p=.004)$ and looking at job ads $(\beta=.27, p=.005)$ explained unique variance in receiving job offers ( $\mathrm{H} 1 \mathrm{~b}$ and $\mathrm{H} 1 \mathrm{c}$ supported; H1a and H1d not supported).

To test the next set of hypotheses (H2a-d) regarding the relationship between specific job search self-efficacies and behaviors, four hierarchical regression analyses were conducted with

\footnotetext{
${ }^{2}$ When we repeated our analyses with one global job search behavior variable instead of the four specific job search behaviors and using the same control variables, we found that global job search behavior positively predicted job offers $(\beta=.55, p<.001)$ and global job search self-efficacy positively predicted global job search behavior $(\beta=.32$, $p<.001)$. Global job search self-efficacy also moderated the relationship between global job search behavior and job offers $(\beta=.16, p=.03)$, such that the relationship was more positive when self-efficacy was higher.
} 
the four different job search behaviors as respective dependent variables. Control variables were added in the first step and the four job search self-efficacies in the second step. As displayed in Table 3, number of children negatively predicted the time ethnic minority women spent on networking ( $\beta=-.22, p=.02)$ and contacting employment agencies $(\beta=-.22, p=.02)$ in their job search. In the second step, the specific job search self-efficacies explained incremental variance in all search behaviors: $9.2 \%$ for networking, $F(4,146)=3.86, p=.005 ; 11.1 \%$ for employment agencies, $F(4,146)=4.73, p=.001 ; 14.1 \%$ for job ads, $F(4,146)=6.11, p<.001$; and $15 \%$ for Internet job search, $F(4,146)=6.47, p<.001$.

However, the results were only partially in line with our Hypotheses 2a-d. In support of H2a, job seekers with stronger networking self-efficacy beliefs reported spending more time on networking in their job search $(\beta=.26, p=.005)$. Moreover, Internet self-efficacy was the only significant predictor of looking for job openings on the Internet $(\beta=.44, p<.001)$, supporting $\mathrm{H} 2 \mathrm{~d}$. In addition to these hypothesized effects, networking self-efficacy positively predicted time spent on contacting employment agencies $(\beta=.21, p=.02)$ and looking at job ads $(\beta=.27, p=.003)$, whereas Internet self-efficacy was a positive predictor of networking $(\beta=.24, p=.03)$ and job ads $(\beta=.32, p=.003)$. Failing to support $\mathrm{H} 2 \mathrm{~b}$ and $\mathrm{H} 2 \mathrm{c}$, agency self-efficacy was not a significant predictor of contacting employment agencies and job ad self-efficacy was not a significant predictor of looking at job ads.

To test the final set of hypotheses (H3a-d) on the moderating role of specific job search selfefficacies, four hierarchical regression analyses were conducted with job offers as the dependent variable. For each regression, the control variables were entered in the first step, one specific job search self-efficacy in the second step, the corresponding specific job search behavior in the third step, and the interaction between the job search self-efficacy and behavior in the fourth step. To 
examine the pattern of the significant interactions, we plotted the expected means and conducted simple slope analyses for high and low $(M \pm 1 S D)$ values of the moderator.

As shown in Table 4, the relationship between time spent networking and number of job offers was moderated by networking self-efficacy $(\beta=.21, p=.004)$, in support of H3a. As illustrated in Figure 1 and corroborated by simple slope analyses, networking was more positively related to receiving job offers when networking self-efficacy beliefs were high (conditional effect at $M+1 S D$ was $.41, S E=.08, p<.001$ ). The relationship was only marginally significant when networking self-efficacy was low (conditional effect at $M-1 S D$ was .13, $S E=.07, p=.06)$.

A similar interaction was observed for looking at job ads $(\beta=.19, p=.006)$, supporting H3c. As shown in Figure 2, the relationship between spending time on job ads and receiving job offers was more positive for job seekers with higher job ad self-efficacy. Simple slope analyses confirmed that this relationship was stronger for high job ad self-efficacy (conditional effect at $M$ $+1 S D$ was $.43, S E=.07, p<.001$ ) than for low job ad self-efficacy (conditional effect at $M-1 S D$ was $.19, S E=.06, p=.002$ ), even though both slopes were significantly positive. The interaction term was not significant for contacting employment agencies and looking for jobs on the Internet, failing to support $\mathrm{H} 3 \mathrm{~b}$ and $\mathrm{H} 3 \mathrm{~d}$.

\section{Discussion}

Even though ethnic minority women represent an especially vulnerable group on the labour market (Kamenou \& Fearfull, 2006; Shen et al., 2017), we know little about how their job search might best be stimulated. Therefore, we set out to examine which specific job search behaviors of unemployed ethnic minority women predict job search success. On a theoretical level, we contribute to the job search literature by investigating specific job search self-efficacies as 
antecedents of ethnic minority women's job search behaviors and as moderators of the effectiveness of these job search behaviors.

First, our results indicate a significant and positive relationship between general job search behavior and the number of job offers received among ethnic minority women, which corroborates prior meta-analytic findings in the general job seeker population (Kanfer et al., 2001). However, we found distinguishable patterns when looking at the specific job search behaviors. Particularly, our findings suggest that contacting employment agencies and going through job ads increase the number of job offers ethnic minority women receive. Moreover, the effect of job ads was more positive for job seekers with higher job ad self-efficacy beliefs. Although prior research on these specific job search behaviors is scarce, Van Hoye et al. (2009) also observed a positive relationship between employment agencies and job offers in the general job seeker population. In that study, job ads were not related to job offers, but no moderators were considered. Theoretically, our findings demonstrate that the specific content and direction of job search behavior should be considered (Kanfer et al., 2001), as distinguishing between specific job search self-efficacies and behaviors enhances our understanding of the job search process and outcomes.

Second, contrary to research findings in the general job seeker population (Van Hoye et al., 2009; Wanberg et al., 2000) and practical recommendations, networking did not have a significant main effect relationship with job offers when other job search behaviors were controlled for. This suggests that the effects of networking in job search might be less beneficial for ethnic minority women, potentially because they typically have less access to high-quality social networks (McDonald et al., 2009). Along these lines, we found that networking selfefficacy moderated the relationship between networking and job offers: only ethnic minority women who felt highly confident about being able to network successfully received more job 
offers when they spent more time networking. Theoretically, in line with recent developments in the job search literature (Van Hooft et al., 2013), this suggests that beyond the mere intensity of engaging in job search behaviors, the quality with which they are performed is of crucial importance.

Third, in line with social cognitive theory (Bandura, 1991), our findings demonstrate the value of specific job search self-efficacy beliefs as determinants of the use and impact of different job search behaviors among ethnic minority women. These findings illustrate the universal importance of self-efficacy for motivational processes (Bandura, 2002). More specifically, as already noted, job ads and networking were more strongly related to receiving job offers for ethnic minority women with higher job ad and networking self-efficacy, respectively. In addition, specific self-efficacy beliefs explained incremental variance in predicting all job search behaviors. However, results with respect to the relationship between corresponding self-efficacies and behaviors were mixed. Networking self-efficacy and Internet self-efficacy were the strongest predictors of networking and Internet job search respectively. However, employment agencies and job ads were not predicted by their corresponding self-efficacy. Instead, these job search behaviors were also predicted by networking and/or Internet self-efficacy. One explanation might be that contacting employment agencies and looking at job ads in newspapers or journals are relatively easy and accessible job search behaviors, such that job seekers might engage in it even if they do not feel entirely confident in their ability to do so. In contrast, networking and using the Internet are likely to require more specific knowledge and skills. This is why networking and Internet self-efficacy might be better indicators of job seekers' overall confidence in being able to conduct a successful job search, thus likely to predict other search behaviors as well.

Finally, we would like to note that ethnic minority women with children seem to be a particularly vulnerable group on the labour market. In our study, women with more children 
received less job offers. This might be explained by the additional job search constraints posed by having children, such as needing affordable day care (Van Hoye \& Lootens, 2013). In fact, we observed that ethnic minority women with more children spent less time on networking and employment agencies - job search behaviors that require leaving the home - whereas no difference was observed for job ads and Internet job search. This is in line with research in the more general job seeker population showing that women with more children are more likely to fully use up the unemployment benefits they are entitled to (and thus to be unemployed for a longer time, Wanberg et al., 2002).

\section{Limitations and Future Research Directions}

This study has some limitations. First, we investigated four prevalent job search behaviors: networking, contacting employment agencies, looking at printed job ads, and looking for jobs on the Internet. It is possible that some search behaviors will be less successful in other contexts or over time (e.g., printed job ads) while other new search behaviors need to be taken into account (e.g., social media postings). Because particular search behaviors might be more beneficial for some groups or under certain conditions, we believe that distinguishing between specific search behaviors (versus a unidimensional approach) is necessary to allow for a more accurate evaluation of the outcomes of job search. In contrast, we propose that the role of specific job search self-efficacy beliefs as determinants of the use and effectiveness of specific search behaviors will translate to a more general job seeker population. Future research should examine this proposition for other samples, settings, job search behaviors, and countries.

Further, our study relied on self-report measures, which may raise issues of common method variance and social desirability responding. However, we sought to reduce the threat of common method variance by temporally and methodologically separating our main predictor and criterion measures (cf. Podsakoff, MacKenzie, Lee, \& Podsakoff, 2003), using a two-wave design with 
different data collection methods (i.e., paper-and-pencil vs. phone interview). Also, not all hypothesized relations were supported and various correlations were low and/or not significant, suggesting that common method variance may not impose a large threat to our conclusions. To reduce social desirability responding, we emphasized the confidentiality of the responses and that they would only be used for research purposes. We also explicitly encouraged participants to answer honestly and ensured them that their answers would in no way affect their official record. Neither we nor the private reemployment counselling agency had anything to do with participants' social benefits. The low means for job search behaviors (ranging between 2.11 and 2.30 on a 5-point Likert scale) and job offers (0.39) further suggest that social desirability responding was not a major concern in our study. In addition, previous research has supported the validity of job search self-reports as these correlated with the number of hours spent on job search (Wanberg et al., 2005), counsellor reports, and objective data logs of job search activity (Van Hooft, 2014). Nevertheless, future research may include other sources to assess job search behaviors, or test the effectiveness of specific job search self-efficacy training interventions.

In terms of other research directions, future research should investigate the antecedents of ethnic minority women's job search self-efficacy beliefs and try to understand why they might be lower than in the general job seeker population. Possibly relevant factors include educational level, language proficiency, and other acculturation-related variables. In addition, future studies should look not only at individuals' confidence in being able to successfully perform specific job search behaviors, but also at the actual quality with which these behaviors are carried out and how this relates to job search self-efficacy beliefs and outcomes (Van Hooft et al., 2013). For instance, web-based job search is likely to be more effective when multiple job boards as well as employer recruitment sites are consulted or when more relevant keywords are used. 


\section{Practical Implications}

First, this study offers key practical implications for ethnic minority women in search of employment as well as for developing policies, counselling, and interventions aimed at this target group. Our results suggest that ethnic minority women should not rely on networking as a single job search strategy, especially when their networking self-efficacy beliefs are not high. Instead, spending more time on contacting employment agencies and looking at printed job ads seems to increase the number of job offers received.

Furthermore, our findings demonstrate the importance of networking and Internet selfefficacy as determinants of engaging in specific job search behaviors. Therefore, job search counselling and interventions should be aimed at enhancing these beliefs. In addition, our results suggest that boosting job seekers' networking self-efficacy might increase the effectiveness of networking. On the basis of social cognitive theory (Bandura, 1991), job search self-efficacy beliefs might be strengthened by providing mastery experiences (e.g., practicing networking conversations), social modelling (e.g., testimonials), and social support (e.g., encouragements from other job seekers in a job search club). Along these lines, prior research has demonstrated that job search training can be effective in enhancing general self-efficacy and reemployment odds (Liu et al., 2014). Future research is needed to test the effectiveness of job search interventions aimed at boosting specific job search self-efficacy beliefs. 


\section{References}

Ajzen, I. (1991). The theory of planned behavior. Organizational Behaviour and Human Decision Processes, 50, 179-211. doi: http://dx.doi.org/10.1016/0749-5978(91)90020-T

Bandura, A. (1991). Social cognitive theory of self-regulation. Organizational Behaviour and Human Decision Processes, 50, 248-287. doi: http://dx.doi.org/10.1016/07495978(91)90022-L

Bandura, A. (2001). Social cognitive theory: An agentic perspective. Annual Review of Psychology, 52, 1-26. doi: https://dx.doi.org/10.1146/annurev.psych.52.1.1

Bandura, A. (2002). Social cognitive theory in cultural context. Journal of Applied Psychology: An International Review, 51, 269-290. doi: https://doi.org/10.1111/1464-0597.00092

Bandura, A., \& Locke, E. A. (2003). Negative self-efficacy and goal effects revisited. Journal of Applied Psychology, 88, 87-99. doi: http://dx.doi.org/10.1037/0021-9010.88.1.87

Blau, G. (1994). Testing a two-dimensional measure of job search behaviour. Organizational Behaviour and Human Decision Processes, 59, 288-312. doi: http://dx.doi.org/10.1006/obhd.1994.1061

Byars-Winston, A., Fouad N., \& Wen, Y. (2015). Race/ethnicity and sex in U.S. occupations, 1970-2010: Implications for research, practice, and policy. Journal of Vocational Behaviour, 87, 54-70. doi: http://dx.doi.org/10.1016/j.jvb.2014.12.003

CBS (2016). Annual report on integration 2016. Den Haag, The Netherlands: CBS.

CBS (2018). Statline [Open data]. Retrieved from http://opendata.cbs.nl/statline/\#/CBS/en

Derous, E., Ryan, A. M., \& Nguyen, H. H. D. (2012). Multiple categorization in resume screening: Examining effects on hiring discrimination against Arab applicants in field and 
lab settings. Journal of Organizational Behavior, 33, 544-570. doi:

http://dx.doi.org/10.1002/job.769

Ellis, R. A., \& Taylor, M. S. (1983). Role of self-esteem within the job search process. Journal of Applied Psychology, 68, 632-640. doi: http://dx.doi.org/10.1037/0021-9010.68.4.632

Hackett, G., \& Byars, A. M. (1996). Social cognitive theory and the career development of African American women. Career Development Quarterly, 44, 322-340. doi:

http://dx.doi.org/10.1002/j.2161-0045.1996.tb00449.x

Henrich, J., Heine, S. J., \& Norenzayan, A. (2010). The weirdest people in the world?, Behavioral and Brain Sciences, 33(2-3), 61-83. doi: http://dx.doi.org/10.1017/S0140525X0999152X

Kamenou, N., \& Fearfull, A. (2006). Ethnic minority women: A lost voice in HRM. Human Resource Management Journal, 16, 154-172. doi: http://dx.doi.org/10.1111/j.17488583.2006.00010.x

Kanfer, R., Wanberg, C. R., \& Kantrowitz, T. M. (2001). Job search and employment: A personality-motivational analysis and meta-analytic review. Journal of Applied Psychology, 86, 837-855. doi: http://dx.doi.org/10.1037//0021-9010.86.5.837

Liu, S., Huang, J. L., \& Wang, M. (2014). Effectiveness of job search interventions: A metaanalytic review. Psychological Bulletin, 140, 1009-1041. doi: http://dx.doi.org/ $10.1037 / \mathrm{a} 0035923$

Luzzo, D. A., \& McWhirter, E. H. (2001). Sex and ethnic differences in the perception of educational and career-related barriers and levels of coping efficacy. Journal of Counseling \& Development, 79, 61-67. doi: https://doi.org/10.1002/j.1556-6676.2001.tb01944.x 
McDonald, S., Lin, N., \& Ao, D. (2009). Networks of opportunity: Gender, race, and job leads. Social Problems, 56, 385-402. doi: http://dx.doi.org/10.1525/sp.2009.56.3.385

Moynihan, L. M., Roehling, M. V., LePine, M. A., \& Boswell, W. R. (2003). A longitudinal study of the relationships among job search self-efficacy, job interviews, and employment outcomes. Journal of Business and Psychology, 18, 207-233. doi: http://dx.doi.org/ 10.1023/A: 1027349115277

Podsakoff, P. M., MacKenzie, S. B., Lee, J. Y., \& Podsakoff, N. P. (2003). Common method biases in behavioral research: A critical review of the literature and recommended remedies. Journal of Applied Psychology, 88, 879-903. doi: http://dx.doi.org/10.1037/00219010.88.5.879

Saks, A. M. (2006). Multiple predictors and criteria of job search success. Journal of Vocational Behavior, 68, 400-415. http://dx.doi.org/10.1016/j.jvb.2005.10.001

Saks, A. M., Zikic, J., \& Koen, J. (2015). Job search self-efficacy: Reconceptualizing the construct and its measurement. Journal of Vocational Behaviour, 86, 104-114. doi: https://doi.org/10.1016/j.jvb.2014.11.007

Shen, W., Sackett, P. R., Lievens, F., Schollaert, E., Van Hoye, G., Steiner, D. D. ... Cook, M. (2017). Updated perspectives on the international legal environment for selection. In Farr, J.L. and Tippins, N.T. (Eds.), Handbook of Employee Selection (2 ed., pp. 659-677). New York, NY: Routledge.

Šverko, B., Galić, Z., Seršić, D. M., \& Galešić, M. (2008). Unemployed people in search of a job: Reconsidering the role of search behavior. Journal of Vocational Behavior, 72, 415-428. doi: http://dx.doi.org/10.1016/j.jvb.2007.11.006

Tempelman, C., Berden, C., \& Kok, L. (2010). Research report: Costs and results of reintegration. Amsterdam, The Netherlands: SEO Economic Research. 
Van Hooft, E. A. J. (2014). Motivating and hindering factors during the reemployment process: The added value of employment counselors' assessment. Journal of Occupational Health Psychology, 19, 1-17. doi: http://dx.doi.org/10.1037/a0035118

Van Hooft, E. A. J., Born, M. P., Taris, T. W., \& Van der Flier, H. (2004a). Job search and the theory of planned behaviour: Minority-majority group differences in The Netherlands. Journal of Vocational Behaviour, 65, 366-390. doi: http://dx.doi.org/10.1016/j.jvb.2003.09.001

Van Hooft, E. A. J., Born, M. P., Taris, T. W., \& Van der Flier, H. (2005). Predictors and outcomes of job search behavior: The moderating effects of gender and family situation. Journal of Vocational Behavior, 67, 133-152. doi: https://doi.org/10.1016/j.jvb.2004.11.005

Van Hooft, E. A. J., Born, M. P., Taris, T. W., Van der Flier, H., \& Blonk, R. W. B. (2004b). Predictors of job search behavior among employed and unemployed people. Personnel Psychology, 57, 25-59. doi: http://dx.doi.org/10.1111/j.1744-6570.2004.tb02483.x

Van Hooft, E. A. J., Wanberg, C. R., \& Van Hoye, G. (2013). Moving beyond job search quantity: Towards a conceptualization and self-regulatory framework of job search quality. Organizational Psychology Review, 3, 3-40. doi: http://dx.doi.org/10.1177/2041386612456033

Van Hoye, G., \& Lootens, H. (2013). Coping with unemployment: Personality, role demands, and time structure. Journal of Vocational Behaviour, 82, 85-95. doi: http://dx.doi.org/ http://dx.doi.org/10.1016/j.jvb.2013.01.004

Van Hoye, G., \& Saks, A. M. (2008). Job search as goal-directed behaviour: Objectives and methods. Journal of Vocational Behaviour, 73, 358-367. doi: http://dx.doi.org/10.1016/j.jvb.2008.07.003

Van Hoye, G., Saks, A. M., Lievens, F., \& Weijters, B. (2015). Development and test of an 
integrative model of job search behaviour. European Journal of Work and Organizational Psychology, 24, 544-559. doi: http://dx.doi.org/10.1080/1359432X.2014.964214

Van Hoye, G., Van Hooft, E. A. J., \& Lievens, F. (2009). Networking as a job search behaviour: A social network perspective. Journal of Occupational and Organizational Psychology, 82, 661-682. doi: http://dx.doi.org/10.1348/096317908X360675

Van Ryn, M., \& Vinokur, A. D. (1992). How did it work? An examination of the mechanisms through which an intervention for the unemployed promoted job-search behaviour. American Journal of Community Psychology, 20, 577-597. doi: http://dx.doi.org/10.1007/BF00941773

Wanberg, C. R., Glomb, T. M., Song, Z., \& Sorenson, S. (2005). Job-search persistence during unemployment: A 10-wave longitudinal study. Journal of Applied Psychology, 90, 411-430. doi: http://dx.doi.org/10.1037/0021-9010.90.3.411

Wanberg, C. R., Hough, L. M., \& Song, Z. (2002). Predictive validity of a multidisciplinary model of reemployment success. Journal of Applied Psychology, 87, 1100-1120. doi: http://dx.doi.org/10.1037/0021-9010.87.6.1100

Wanberg, C. R., Kanfer, R., \& Banas, J. T. (2000). Predictors and outcomes of networking intensity among unemployed job seekers. Journal of Applied Psychology, 85, 491-503. doi: http://dx.doi.org/10.1037//0021-9010.85.4.491

Wanberg, C. R., Kanfer, R., Hamann, D. J., \& Zhang, Z. (2016). Age and reemployment success after job loss: An integrative model and meta-analysis. Psychological Bulletin, 142, 400-426. doi: https://dx.doi.org/10.1037/bul0000019

Wanberg, C. R., Zhu, J., \& Van Hooft, E. A. J. (2010). The job search grind: Perceived progress, self-reactions, and self-regulation of search effort. Academy of Management Journal, 53, 788-807. doi: http://dx.doi.org/10.5465/amj.2010.52814599 
Table 1

Means, Standard Deviations, and Correlations between Study Variables

\begin{tabular}{|c|c|c|c|c|c|c|c|c|c|c|}
\hline Variable & $M$ & $S D$ & 1 & 2 & 3 & 4 & 5 & 6 & 7 & 8 \\
\hline \multicolumn{11}{|l|}{ Time 1 variables } \\
\hline 1. Age & 36.28 & 9.75 & - & & & & & & & \\
\hline 2. Primary school ${ }^{\mathrm{a}}$ & .74 & .44 & .07 & - & & & & & & \\
\hline 3. College ${ }^{a}$ & .07 & .25 & .02 & $-.46 * *$ & - & & & & & \\
\hline 4. Children & 1.80 & 1.45 & $.52 * *$ & .07 & -.02 & - & & & & \\
\hline 5. Networking self-efficacy & 3.43 & 1.29 & .07 & -.06 & .12 & .05 & - & & & \\
\hline 6. Agency self-efficacy & 3.13 & 1.23 & $.23 * *$ & .00 & .08 & .10 & $.45^{* *}$ & - & & \\
\hline 7. Job ad self-efficacy & 3.97 & 1.03 & .10 & -.06 & .09 & -.16 & .05 & $.44 * *$ & - & \\
\hline 8. Internet self-efficacy & 3.29 & 1.26 & $.16^{*}$ & -.03 & .12 & .08 & $.17 *$ & $.55^{* *}$ & $.55^{* *}$ & - \\
\hline
\end{tabular}

Time 2 variables

\begin{tabular}{lccccccccccccccc} 
9. Networking & 2.19 & .89 & -.02 & -.09 & .06 & -.15 & $.21^{* *}$ & .02 & -.03 & .09 & - & \\
10. Employment agencies & 2.11 & .91 & -.03 & -.04 & .09 & $-.15^{*}$ & $.22^{* *}$ & $.22^{* *}$ & $.16^{*}$ & $.26^{* *}$ & $.60^{* *}$ & - & \\
11. Job ads & 2.30 & .89 & -.06 & -.09 & -.00 & -.09 & $.23^{* *}$ & .14 & .12 & $.25^{* *}$ & $.61^{* *}$ & $.64^{* *}$ & - \\
12. Internet & 2.20 & 1.07 & -.01 & -.01 & .03 & -.01 & .13 & $.17 *$ & .14 & $.35^{* *}$ & $.51^{* *}$ & $.75^{* *}$ & $.62^{* *}$ & - \\
13. Job offers & .39 & .63 & -.04 & -.11 & .08 & -.14 & .09 & .12 & .14 & $.18^{*}$ & $.44^{* *}$ & $.50^{* *}$ & $.50^{* *}$ & $.41^{* *}$ \\
\hline
\end{tabular}

Note. Due to missing values, $N$ ranges from 162 to 188 .

a Two dummy variables (primary school and college) were created to represent the three categories of education measured in our study, with the middle category (high school) used as the reference group.

$* p<.05 . * * p<.01$. 
Table 2

Hierarchical Regression Predicting Job Offers From Job Search Behaviors

\begin{tabular}{|c|c|c|}
\hline \multirow[b]{2}{*}{ Predictor } & \multicolumn{2}{|c|}{ Job offers } \\
\hline & Step 1 & Step 2 \\
\hline \multicolumn{3}{|l|}{ Control variables } \\
\hline Age & .06 & .00 \\
\hline Primary school ${ }^{\mathrm{a}}$ & -.11 & -.08 \\
\hline College $^{a}$ & .05 & .06 \\
\hline Children & $-.19 *$ & -.06 \\
\hline \multicolumn{3}{|l|}{ Job search behaviors } \\
\hline Networking & & .12 \\
\hline Employment agencies & & $.33^{* *}$ \\
\hline Job ads & & $.27 * *$ \\
\hline Internet & & -.08 \\
\hline$R^{2}$ & .048 & $.377 * *$ \\
\hline Adjusted $R^{2}$ & .023 & $.343 * *$ \\
\hline$\Delta R^{2}$ & .048 & $.328 * *$ \\
\hline
\end{tabular}

Note. $N=155$. The values in the table are standardized beta weights $(\beta)$.

${ }^{\mathrm{a}}$ Two dummy variables (primary school and college) were created to represent the three categories of education measured in our study, with the middle category (high school) used as the reference group.

$* p<.05 . * * p<.01$. 
Table 3

Hierarchical Regression Predicting Job Search Behavior From Job Search Self-Efficacy

\begin{tabular}{|c|c|c|c|c|c|c|c|c|}
\hline \multirow[b]{2}{*}{ Predictor } & \multicolumn{2}{|c|}{ Networking } & \multicolumn{2}{|c|}{$\begin{array}{c}\text { Employment } \\
\text { agencies }\end{array}$} & \multicolumn{2}{|c|}{ Job ads } & \multicolumn{2}{|c|}{ Internet } \\
\hline & Step 1 & Step 2 & Step 1 & Step 2 & Step 1 & Step 2 & Step 1 & Step 2 \\
\hline \multicolumn{9}{|l|}{ Control variables } \\
\hline Age & .12 & .12 & .11 & .06 & .04 & .01 & .01 & -.03 \\
\hline Primary school $^{\mathrm{a}}$ & -.03 & -.03 & -.01 & -.01 & -.10 & -.08 & -.04 & -.03 \\
\hline College $^{a}$ & .02 & -.02 & .03 & -.01 & -.08 & -.12 & -.01 & -.04 \\
\hline Children & $-.22 *$ & $-.24 *$ & $-.22 *$ & $-.22 *$ & -.11 & -.12 & .00 & -.01 \\
\hline \multicolumn{9}{|l|}{ Job search self-efficacy } \\
\hline Networking self- & & $.26^{* *}$ & & $.21 *$ & & $.27 * *$ & & .13 \\
\hline \multicolumn{9}{|l|}{ efficacy } \\
\hline Agency self-efficacy & & -.12 & & .02 & & -.13 & & -.09 \\
\hline Job ad self-efficacy & & -.12 & & -.01 & & -.02 & & -.10 \\
\hline Internet self-efficacy & & $.24 *$ & & .21 & & $.32 * *$ & & $.44 * *$ \\
\hline$R^{2}$ & .037 & $.129 * *$ & .035 & $.153 * *$ & .018 & $.158 * *$ & .001 & $152 * *$ \\
\hline Adjusted $R^{2}$ & .012 & $.082 * *$ & .010 & $.099 * *$ & -.009 & $.112 * *$ & -.025 & $105^{* *}$ \\
\hline$\Delta R^{2}$ & .037 & $.092 * *$ & .035 & $.111 * *$ & .018 & $.141 * *$ & .001 & $150 * *$ \\
\hline
\end{tabular}

Note. $N=155$. The values in the table are standardized beta weights $(\beta)$.

${ }^{a}$ Two dummy variables (primary school and college) were created to represent the three categories of education measured in our study, with the middle category (high school) used as the reference group.

$* p<.05 . * * p<.01$. 
Table 4

Hierarchical Regression Testing the Moderation Effects of Job Search Self-Efficacy on Job Offers

\begin{tabular}{lcccc}
\hline Predictor & \multicolumn{5}{c}{ Job offers } \\
\hline Control variables & & & \\
Age & .01 & -.01 & .02 & .04 \\
Primary school $^{\mathrm{a}}$ & -.11 & -.10 & -.05 & -.09 \\
College $^{\mathrm{a}}$ & .03 & .04 & .11 & .08 \\
Children & -.09 & -.08 & -.13 & $-.18^{*}$
\end{tabular}

Job search self-efficacy

Networking self-efficacy

Agency self-efficacy

.04

Job ad self-efficacy

Internet self-efficacy

.08

Job search behaviors

Networking

$.43^{* *}$

Employment agencies

$.51^{* *}$

Job ads

$.48 * *$

Internet

\section{Interactions}

Networking self-efficacy $\times$ Networking

Agency self-efficacy $\times$ Employment agencies

.04

Job ad self-efficacy $\times$ Job ads

$.19 * *$

Internet self-efficacy $\times$ Internet

$R^{2}$

$\begin{array}{rrrr}.298 * * & .319 * * & .349 * * & .232 * * \\ .264 * * & .287 * * & .318 * * & .195 * *\end{array}$

Adjusted $R^{2}$

Note. $N=155$. The values in the table are standardized beta weights $(\beta)$ for the final step of each regression.

a Two dummy variables (primary school and college) were created to represent the three categories of education measured in our study, with the middle category (high school) used as the reference group.

* $p<.05$. ** $p<.01$. 


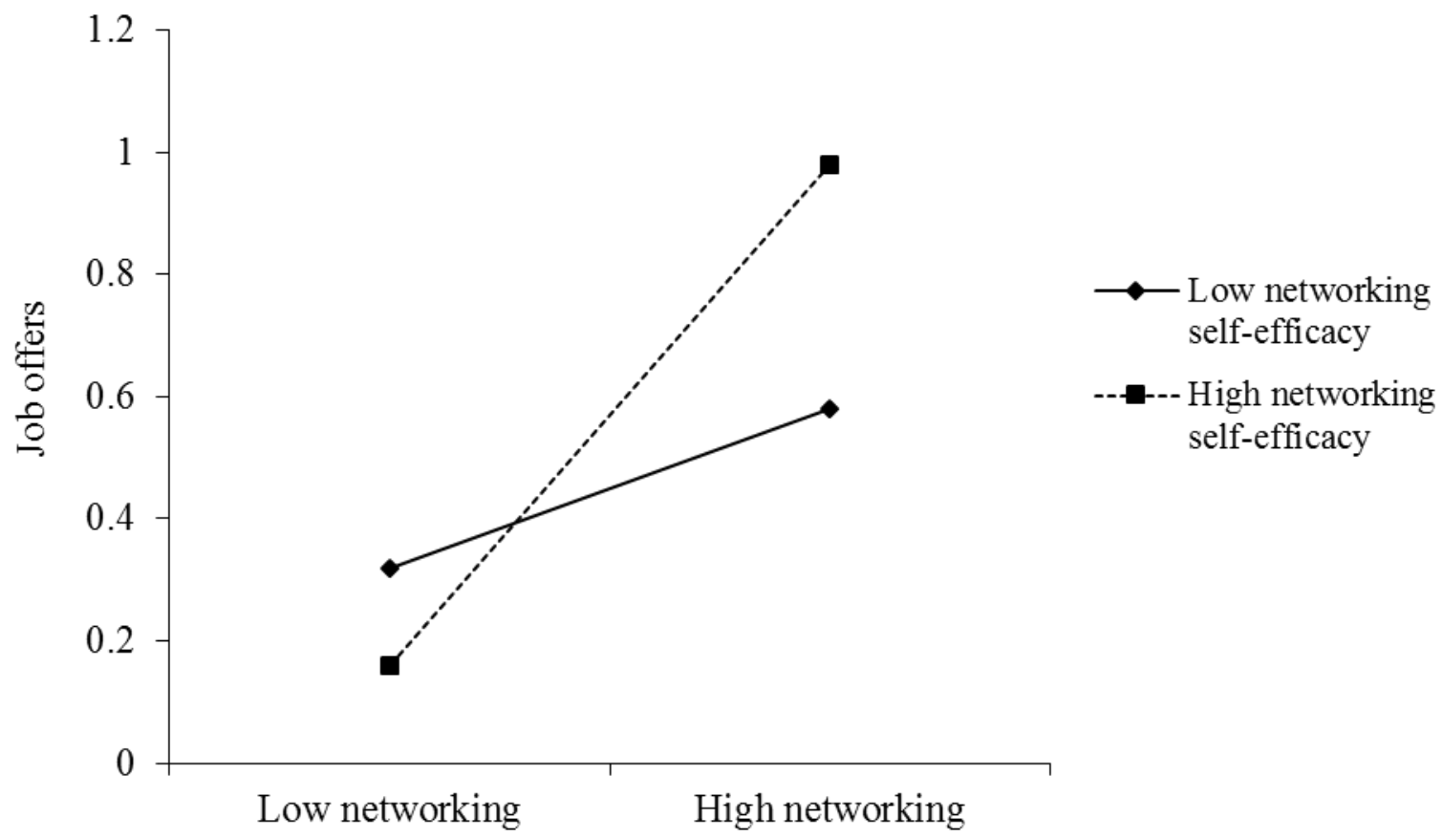

Figure 1. Simple regression slopes of job offers on networking for low $(M-1 S D)$ and high $(M+$ $1 S D)$ levels of networking self-efficacy. 


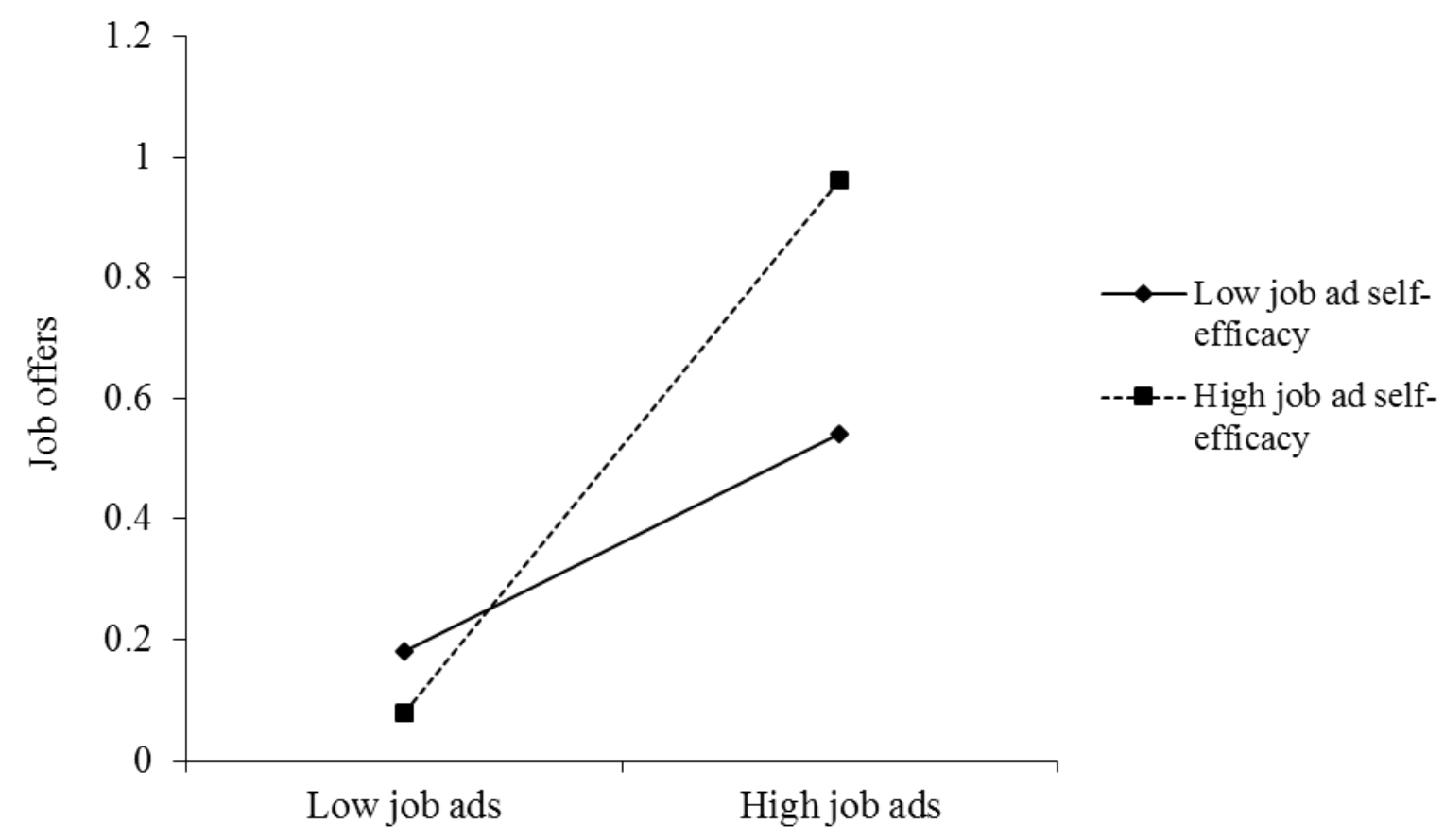

Figure 2. Simple regression slopes of job offers on job ads for low $(M-1 S D)$ and high $(M+$ $1 S D)$ levels of job ad self-efficacy. 